Alma Mater Studiorum - Università di Bologna DEPARTMENT OF ECONOMICS

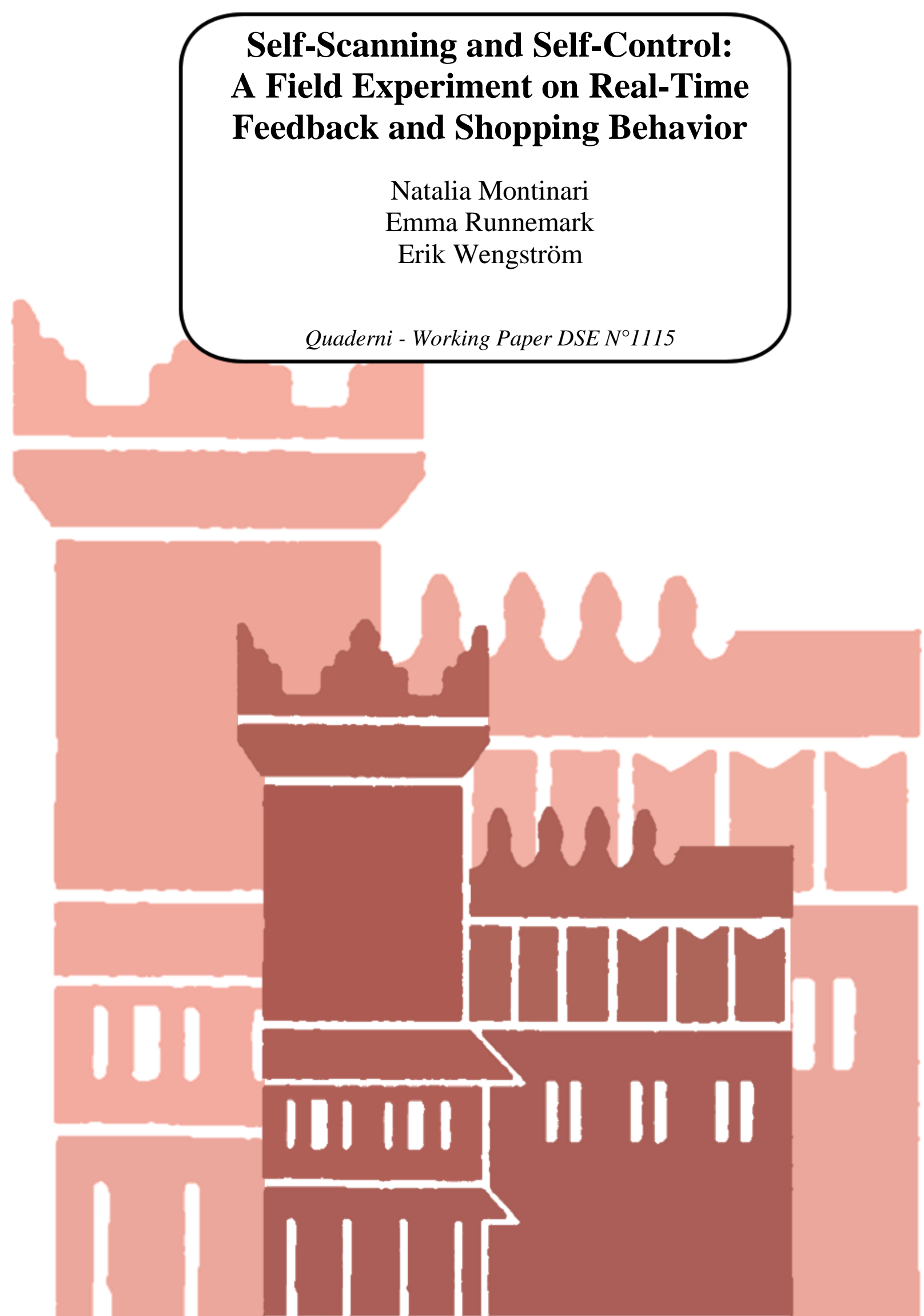




\title{
Self-Scanning and Self-Control: A Field Experiment on Real-Time Feedback and Shopping Behavior*
}

\author{
Natalia Montinari ${ }^{\dagger}$ Emma Runnemark, ${ }^{\ddagger}$ and Erik Wengström ${ }^{\S}$
}

November 2017

\begin{abstract}
Payment and checkout at retail stores is increasingly being replaced by automated systems. One recent technological invention in this area is mobile self-scanning in which customers carry a mobile scanner while shopping. Mobile self-scanners give real-time feedback on spending. The device increases price saliency and enables customers to keep track of the total amount spent. Using a field experiment, we test if mobile self-scanning affects shopping behavior. Consumers of two grocery stores were allocated randomly to use a mobile self-scanner or not. Overall, we find that using the self-scanner has a negative but insignificant effect on total amount spent. However, the response to using the scanner is heterogeneous and for customers with low self-control, it significantly reduces both their spending and number of items bought when using the mobile scanner. Moreover, we find that consumers with low self-control are more likely to use the self-scanner than individuals with high self-control. Taken together, our results suggest that sophisticated individuals, that is, individuals who are aware of their self-control problem, use the scanner to control their spending.
\end{abstract}

JEL classification: D01; D12; M30

Keywords: Self-scanning; Self-control; Shopping Behavior; Real-time Feedback; Field Experiment

${ }^{*}$ This paper has benefited from comments made by seminar participants at the Aarhus University, University of Copenhagen, University of Lille and participants at ESA Meetings in Bergen and Richmond. We acknowledge generous funding from Handelns utvecklingsråd and Riksbankens Jubileumsfond. We are deeply thankful for excellent research assistance provided by Frida Erlandsson, Sofia Frögelius, Erik Grenestam, Hjördis Hardardottir, Måns Hägerdal, Karl McShane, Fredrik Paulsson, Henrik Siljebråt, Anna Welander. Natalia Montinari's contribution was performed while she was a researcher at the Department of Economics of the Lund University, Sweden. The usual disclaimer applies.

${ }^{\dagger}$ Bologna University; E-mail: natalia.montinari2@unibo.it.

${ }^{\ddagger}$ Lund University. Author deceased.

${ }_{\S}^{\S}$ Lund University; E-mail: erik.wengstrom@nek.lu.se. 


\section{Introduction}

Technology that provides feedback about behavior is becoming increasingly popular in many different areas of life. Electronic fitness trackers report instant health statistics, modern cars show current fuel consumption and smartphone apps give feedback on everything from personal finances to web-browsing habits. Such technology is also spreading to many shopping contexts. To asses how feedback technology influence shopping behavior, we conducted a field experiment in a grocery store. In particular, we tested how the use of handheld self-scanners affect the total amount people spend. With the mobile self-scanning device, the customer scans product barcodes while shopping. Immediately after successfully scanning a barcode, the price of the product is displayed on the screen together with an update on the total amount spent. Hence, the scanner places attention on costs and provides feedback about the total amount spent.

Previous research has documented that a large fraction of shoppers are inattentive to prices. Dickson \& Sawyer (1990) report that more than half of the shoppers they approached were not aware of the price of the item they just put in their shopping cart. ${ }^{1}$. The presence of price inattention together with the fact that many shopping decisions are unplanned Inman et al. 2004) suggest that feedback technology that puts attention on prices has a great potential for affecting in-store decision making.

There are many possible mechanisms in which feedback can affect behavior. Feedback can remind people about personal goals and make them attentive of the pros and cons of an action. Reminders have been reported to affect behaviors in various contexts including savings (Karlan et al. 2016), checking overdrafts (Stango \& Zinman 2014), healthy behavior (Milkman et al. 2011) and education (Calzolari \& Nardotto 2016). Relatedly, feedback also increases the salience of certain aspects of the decision environment, which can have dramatic effects on behavior. Using a field experiment in a grocery store, Chetty et al. (2009) found that tax-inclusive price tags in a supermarket reduced demand by 8 percent. Feedback also facilitates numeric calculations, making it easier for people to get an overview of the aggregate effects of individual actions.

It is likely that effects of real-time feedback on shopping behavior are heterogeneous and differ according to consumer characteristics. There is ample evidence that limited attention, self-control and numerical capabilities impair decision making. Specifically, an increasing body of evidence shows that people with low self-control have problems acting in line with their long-run self-interests, resulting in compulsive consumption (Achtziger et al. 2015) and credit card debt (Meier \& Sprenger 2010). Baumeister (2002) and Baumeister et al. (2008) highlight the relevance of self-control failure as a cause of impulsive purchasing. Three main causes of self-control failures identified in these studies are: $i$ ) conflicting goals (e.g., feeling

\footnotetext{
${ }^{1}$ Inattention to prices may also explain why shoppers are unresponsive to quantity surcharges (Clerides \& Courty 2017)
} 
better immediately by buying an item vs the goal of saving money); ii) failure to keep track or monitor one's own behavior; iii) depletion of resources and energies related to selfcontrol, which make self-control less effective, thereby hampering the decision-making process. Feedback technology that makes the cost salient may help present biased consumers to keep spending impulses at bay through all three channels. Consumers can $i$ ) focus on the goal of cost control, ii) more easily monitor behavior, and iii) spend less cognitive resources by keeping track of total expenditures.

In our field experiment, we randomly asked shoppers at the store entrance to either use the self-scanning device or not. At the checkout, we collected background information about the customers and specifically assessed their self-control using the brief self-control scale (Tangney et al. 2004). Overall, we find a negative but insignificant effect on total amount spent of using the self-scanner. However, for those scoring low on the self-control test, the effect is much stronger and highly significant. The effect is sizeable and driven by a drop in the number of items shopped. We also find that those who score low on the self-control test are more likely to have used the scanner prior to our study. One plausible interpretation of our results is hence that shoppers with low self-control are aware of their problems and choose to use the self-scanner as a commitment device to curb compulsive buying.

To the best of our knowledge, our study is the first to study the effects of mobile selfscanning on shopping behavior. Feedback technology such as mobile self-scanners and smart shopping carts are becoming increasingly popular and the use of mobile self-scanners is estimated to grow with an annual rate of 47 percent in Europe (Wincor-Nixdorf 2015). Moreover, the popularity of the technology is expected to increase with new smartphone apps offering similar services. As such, the technology is part of an important naturally occurring shopping environment but also severs as a testbed for how feedback more generally affects people's economic decision making. We are also the first to study the interaction between self-control and real-time feedback devices. On a methodological note, we believe our study provides an example of the usefulness of field experiments for understanding shopping behavior (for a general discussion of field experiments in marketing research see Gneezy 2017). We contribute to the literature on feed-back technology and its relation to in-store decision making and our findings offer useful implications for marketing practice by highlighting the scope for self-scanning technology to enhance consumers' shopping experience.

The study most closely resembling ours is van Ittersum et al. (2013), in which customers are endowed with a tablet, on which they could enter prices to track the total amount spent. It should however be noted that the technology in this study is not a naturally occurring grocery store feature and the calculations done by the subjects are not tied to the payment. Subjects are hence not forced to enter prices into the calculator but merely have the option to do so. In contrast, the scanning technology we use is an embedded part of the grocery store and shoppers are required to scan all products, as the data forms the basis for payment 
at the checkout. This difference also implies that they estimate the effect on customers that are not accustomed to the technology, whereas our participants in general have experience with the device. Yet, another important difference is that van Ittersum et al. (2013) focus on the distinction between budget shoppers, i.e., shoppers that in their studies are assigned an upper limit on their spending, while our focus is on shoppers with self-control problems. They report that the shopping calculator enables budget shoppers to get closer to their budget limits and thereby increase their total spending. Non-budget shoppers, on the other hand, cut their total spending. In our questionnaire, we also ask whether the participants are on a budget or not, and the results are in line with the findings of van Ittersum et al. (2013). Shoppers that report being on a budget generally shop less, but shop significantly more when using the scanner. Hence, we corroborate the findings of van Ittersum et al. (2013) using budgets imposed by the shoppers instead of budgets externally provided by the researchers.

The remainder of the paper is organized as follows. Section 2 describes the design of the experiment and states the hypotheses. Section 3 gives a descriptive overview of the data. Section 4 presents our results and Section 5 contains a concluding discussion.

\section{Experimental Design and Research Hypotheses}

In this section, we outline the design of our field experiment and state our reserach hypothesis.

\subsection{Experimental Procedures}

The data collection was conducted in two supermarkets of the chain City Gross in Sweden, located in the suburbs of Malmö and Lund, predominantly accessed by car.

Our experimental manipulation consisted of randomly assigning shoppers to use a mobile self-scanning device or not. When using the device, customers scan the bar code of each item before packing it into bags. After an item has been successfully scanned, the price of the item appears on the scanner display, along with costs of the preceding items bought as well as the total amount spent. At the end of the shopping trip, customers pay at a scanner terminal where it is possible to use both credit cards and cash.

Eligible participants were consumers who had a loyalty card, since they could immediately start self-scanning without having to sign up. We also excluded groups and families and only targeted people shopping alone or in pairs with another adult. After entering the shop, potential participants were approached and asked whether they had a loyalty card, if they had used a scanner before and whether they were willing to participate in a study. At this stage, they were informed that participating in the study would imply being randomly assigned to using a self-scanner or not. We provided this information before the actual treatment assignment to minimize sample selection issues, due to differences in attrition rates between treatments. With our procedure, customers with a strong preference for using, or 
not using, the scanner would opt out before the treatment allocation. We then provided information about whether they were assigned to use a self-scanner or not. The analysis reported in Section 5 of Online Appendix shows that dropouts do not vary systematically across treatments at different stages before and after the treatment assignment. The Online Appendix also contains details of the logistics of the experiment, on the use of the scanners and on the information displayed on the screen of the scanners.

Participants who agreed to participate also agreed to leave their shopping receipt (or a copy of it) with a research assistant at the store exit, fill in a survey, and receiving a lottery ticket worth 30 SEK (Trisslott) for their participation. Data was collected on both weekdays and weekends in October and November 2014. The experiment was conducted in Swedish. Details about the experimental procedures and the survey are available in Section 7 of the Online Appendix.

The survey consisted of questions regarding $i$ ) socio-economic background of the consumer and his/her household (e.g., age, occupation, education, income class, size and composition of household, etc.); ii) shopping habits, experience with self-scanning and general attitudes towards technology; iii) self-control and patience; $i v$ ) some brief questions of other personality traits, such as attitude towards being a maximizer and financial numeracy.

Self-control was elicited via the 13-item Brief Self-Control Scale (BSCS) elaborated by Tangney et al. (2004). The scale is constructed by asking participants to rate statements relating to self-control and discipline using 5-point Likert scales ranging from 1 (Completely disagree) to 5 (Completely agree) and thereafter summing the scores across the 13 statements. The statements include: "I am good at resisting temptation", "I have trouble concentrating" and "I have a hard time breaking bad habits".

Along similar lines, 5-point Likert scales were used to elicit patience and decision making style (i.e. their attitudes towards being a "maximizer" or "satisficer')'. For patience they stated to which extent they agreed with the following statement "I am in general a person who shows great patience". For decision making style we used two statements from the Maximization Scale (MS) developed by Schwartz et al. (2002): 1) "No matter how satisfied I am with my job, it's only right for me to be on the lookout for better opportunities" and 2) "When I am in the car listening to the radio, I often check other stations to see if something better is playing, even if I am relatively satisfied with what I'm listening to". Higher scores indicate a tendency to be a maximizer that optimizes when making decisions. Lower scores are indicative of satisficing behavior and a tendency to use shortcuts when making decisions and to settle for a "good-enough" option that passes a "threshold of acceptability".

The two numeracy questions followed Lusardi \& Mitchell (2008) and were included to gain a measurement of the subjects' understanding of numbers, basic arithmetic and basic financial literacy. ${ }^{2}$

\footnotetext{
${ }^{2}$ The first question on basic arithmetic asks: "If 5 people all have the winning numbers in the lottery and the prize is 2 million, how much will each of them receive?." The second question measures basic financial
} 


\subsection{Research Hypotheses}

Our research is based on four research hypotheses, stated below.

Hypothesis 1 Self-scanning increases attention on costs (and thus reduces spending) compared to traditional cashier shopping.

The first hypothesis is derived from previous studies, evidencing that i) making costs salient reduces spending Chetty et al. (2009); and ii) providing feedback facilitates numeric calculations, making salient the aggregate effects of individual actions (Karlan et al. 2016). If these effects are associated with the use of the self-scanner, then we should observe a difference in spending between the two treatment groups.

The second hypothesis refers to a specific group of individuals, i.e., those who have low self-control.

Hypothesis 2 The effect of self-scanning is stronger for individuals with low self-control.

Increasing price salience and providing information on total spending is likely to have a stronger effect for those prone to impulsive buying. There is ample evidence showing that low self-control is linked to impulsive shopping (see for example Achtziger et al. 2015 and Baumeister et al. 2008). Hence, we hypothesize that those with low self-control will react stronger to using the self-scanner. The literature on self-control identifies two types of individuals: sophisticated or naive about their future self-control problems, O'Donoghue \& Rabin (1999). The self-control scale that we use identifies sophisticated individuals, that is, those who, having a problem, are aware of it. We expect that the increase in cost salience will be particularly beneficial for sophisticated individuals, helping them to better control their spending compared to a situation in which the self-scanner is not used.

Hypothesis 3 refers to the length of the shopping trip depending on the use of self-scanner.

Hypothesis 3 Self-scanning reduces the length of the shopping trip compared to traditional cashier shopping.

This hypothesis is based on the fact that most grocery shop chains advertise self-scanning as a possibility to reduce wait times by skipping the checkout lane as well as time spent placing items on the supermarket cash register, waiting for the cashier to scan them, and packing them again. ${ }^{3}$ We expect that customers who use the self-scanner are faster than

literacy and asks: "Let's say you have 200 kronor in a savings account. The account earns ten percent interest per year. How much would you have in the account at the end of two years?".

${ }^{3}$ Waitrose (UK) offers a mobile application for self-scanning called "Quick Check",

link here, TESCO (UK) has the "Scan as you Shop" device, described as "It's a quick and simple way for 
those who don't and have to pass through the cashier. If this hypothesis is not supported, this would suggest that for self-scanner users, the time gained at the moment of checkout is compensated by the time lost when scanning (e.g., in finding the bar code of each product to be scanned) and/or when packing the items bought during the shopping trip rather than at the end, after the cashier has completed the scanning.

Hypothesis 4 refers to the impact of self-scanning on individuals who have low self-control.

Hypothesis 4 For individuals with low self-control self-scanning increases the length of the shopping trip.

Hypothesis 4 is closely related to Hypothesis 2, and it speculates on the mechanism inducing individuals with low self-control to reduce their spending when using the self-scanner. By increasing the salience of the total amount spent and the additional costs associated with each new item bought, we expect that self-scanning induces individuals who have low self-control to spend some time thinking about buying a specific item or not, and therefore to slow down.

\section{Summary Statistics}

Table 1 reports the summary statistics for our variables of interest divided into three groups: $i$ ) basic information about the shopping trip and observable characteristics reported in Panel A; ii) self-reported information about socio-economic characteristics, the household composition and shopping habits elicited in the final survey, reported in Panel B, and iii) personality traits elicited using psychological scales in the final survey, reported in Panel C. Columns 6 and 7 report the mean for each variable of interest in the treatment and the control groups while the last column reports results from a set of $\chi^{2}$ tests or two sample $t$-tests, assessing whether the variables are equally distributed in the two groups. In this section, we only comment on the most relevant information displayed in the table and refer to the Online Appendix for a detailed analysis.

Consider Panel A first. Half of the participants $(N=218 / 439)$ were randomly assigned to the treatment (i.e., asked to use the self-scanner while shopping). The average amount spent was 449 SEK and on average 21 items were bought on the shopping trip. It can be noted that our data displayed a large variation in the amount spent (ranging from 21 SEK to 1,944 SEK) as well as in the number of items bought (from 1 to 88).The average length of a shopping trip was of about 26 minutes. ${ }^{4}$ When looking at the relationship between the

Clubcard members to shop", link here COOP (Italy) names the self-scanner "Salva Tempo", literally: "Save Time", link here. The mobile applications "SCAN IT!" and "Stop \& Shop SCAN IT! Mobile" are very popular in the USA.

${ }^{4}$ The length of the shopping trip is calculated by subtracting the time of exit printed on the receipt from the time registered by the experimenter on the report sheet. We excluded from the analysis 10 observations: 2 for which the length of the shopping trip was negative, which was likely due to a mistake in the annotated 
treatment assignment and the observed variables displayed in the last column of Table 1, we do not find any significant association for the variables reported in Panel A.

Table 1: Summary statistics and tests on treatment assignment

\begin{tabular}{|c|c|c|c|c|c|c|c|c|}
\hline Variable & $\begin{array}{c}\text { Mean } \\
\mathrm{S}+\mathrm{T}\end{array}$ & $\begin{array}{l}\text { Std. Dev. } \\
\text { S+T }\end{array}$ & Min. & Max. & $\mathrm{N}$ & $\begin{array}{c}\text { Mean S } \\
\text { (Treatment) }\end{array}$ & $\begin{array}{l}\text { Mean NS } \\
\text { (Control) }\end{array}$ & $\begin{array}{l}\text { Treatment } \\
\text { assignment }\end{array}$ \\
\hline Treatment $(\mathrm{S})$ & 0.47 & 0.50 & 0 & 1 & 439 & - & - & - \\
\hline Total amount spent (SEK) & 449.31 & 366.57 & 21.06 & 1944.2 & 439 & 431.41 & 466.96 & $p=0.310$ \\
\hline \# items bought & 21.17 & 16.09 & 1 & 88 & 439 & 20.78 & 21.56 & $p=0.703$ \\
\hline Using Cash & 0.13 & 0.34 & 0 & 1 & 439 & 0.12 & 0.14 & $p=0.711$ \\
\hline Length of shopping trip (minutes) & 26.08 & 15.59 & 1 & 108 & 429 & 26.90 & 25.26 & $p=0.274$ \\
\hline Average time used per item (minutes) & 1.75 & 1.63 & 0.2 & 16 & 429 & 1.82 & 1.68 & $p=0.352$ \\
\hline Shopping alone & 0.66 & 0.48 & 0 & 1 & 432 & 0.65 & 0.66 & $p=0.757$ \\
\hline Female 1 & 0.70 & 0.46 & 0 & 1 & 427 & 0.70 & 0.72 & $p=0.825$ \\
\hline
\end{tabular}

Panel B. Socio-economic background and shopping habits

\begin{tabular}{|c|c|c|c|c|c|c|c|c|}
\hline Age (years) & 49.86 & 14.38 & 15 & 88 & 437 & 49.09 & 50.63 & $p=0.263$ \\
\hline Income Class & 2.80 & 1.70 & 0 & 6 & 426 & 2.72 & 2.87 & $p=0.389$ \\
\hline Size of Household & 1.95 & 0.69 & 1 & 8 & 432 & 1.95 & 1.95 & $p=0.424$ \\
\hline \# Children (0-18) in the Household & 0.59 & 0.92 & 0 & 5 & 435 & 0.61 & 0.56 & $p=0.681$ \\
\hline Education & 1.46 & 0.75 & 0 & 3 & 437 & 1.46 & 1.46 & $p=0.416$ \\
\hline Scanner User & 0.83 & 0.38 & 0 & 1 & 439 & 0.89 & 0.77 & $p=0.001$ \\
\hline \# scan in last ten shopping trips & 7.90 & 3.52 & 0 & 10 & 358 & 7.89 & 7.92 & $p=0.947$ \\
\hline Budget Constrained & 0.08 & 0.27 & 0 & 1 & 439 & 0.06 & 0.10 & $p=0.234$ \\
\hline Bought Everything Planned & 0.19 & 0.40 & 0 & 1 & 439 & 0.17 & 0.21 & $p=0.309$ \\
\hline
\end{tabular}

Bought Everything Planned

Panel C. Personality traits

\begin{tabular}{lcccccccc}
\multicolumn{1}{c}{ Panel C. Personality traits } & & & \\
\hline Basic Arithmetic & 0.78 & 0.41 & 0 & 1 & 439 & 0.77 & 0.79 & $p=0.591$ \\
Financial Literacy & 0.44 & 0.50 & 0 & 1 & 439 & 0.42 & 0.45 & $p=0.459$ \\
Patience & 3.71 & 1.06 & 1 & 5 & 422 & 3.65 & 3.79 & $p=0.447$ \\
MS (total) & 5.79 & 1.94 & 2 & 10 & 408 & 5.84 & 5.75 & $p=0.087$ \\
BSCS (total) & 46.84 & 6.89 & 26 & 64 & 398 & 46.69 & 47.00 & $p=0.433$ \\
Low Self-control & 0.27 & 0.44 & 0 & 1 & 398 & 0.27 & 0.26 & $p=0.821$
\end{tabular}

Consider now Panel B, displaying the participants' socio-economic backgrounds and shopping habits. Also, for these variables, we do not find any significant association with the treatment assignment except for a difference in the percentage of individuals using the selfscanner, with participants who were randomly assigned to the treatment also reporting being more likely to have used the scanner compared to those who were not assigned ( 0.89 vs 0.77 , $t=3.436, p=0.001)$. This difference is somewhat puzzling, since participants were informed that the experiment may entail using the scanner before they were assigned to treatment and the attrition after treatment assignment was very low (see Section 5 of the Online Appendix). ${ }^{5}$

starting time and 8 for which the length was above 120 minutes, as these individuals may have been distracted by something during the shopping trip e.g. a phone call. According to a Fisher's exact test, there were no significant differences when looking at the treatment assignment of the 10 excluded observations: $p=0.338$.

${ }^{5}$ Note that the question about the use of self-scanner was asked before the treatment assignment was communicated to the participants. 
However, Table 1 contains more than 25 tests so this finding may simply be an effect of mass significance and random variation. When asked about their last 10 shopping trips, $61.45 \%$ $(N=220 / 358)$ declare having always used the scanner, while $11.73 \%(N=42 / 358)$ having never used it.

The variable budget constrained is defined by asking participants whether they had an upper limit on spending on the day of participation: only the $8.00 \%(N 35 / 439)$ of the participants declared so. The Online Appendix (Section 2) contains a detailed discussion of the associations between the different variables contained in Panel B.

Finally, consider the information contained in Panel C, about personality traits. From the last column of Table 1we see the treatment differences regarding decision making style (MS) and self-control (BSCS) are not significant. Participants' score on the BSCS is 46.8, suggesting that participants report a quite high self-control (the maximum value of the BSCS is 65, indicating awareness of high self-control and Tangney et al. (2004) report average values of around 39-40.). Figure 5 in the Online Appendix illustrates the distribution of the total BSCS in our sample. Given the focus of our analysis, in the next subsection we analyze in details the relationship between self-control and other variables.

\subsection{Self-Control}

We identify individuals with low self-control depending on whether their BSCS score belongs to the first quartile of the distribution. In this way, 106 out of 398 individuals with $B S C S \leq$ 42 are classified as having low self-control. Throughout the paper, we will refer to these individuals as the Low self-control group and compare them to Other individuals constituting those belonging to the other three quartiles of the BSCS distribution. ${ }^{6}$ We find that the allocation of individuals to the low self-control group depending on their BSCS score is not significantly associated with the treatment assignment, $\left(\chi^{2}(1)=0.0514, p=0.821\right)$.

Low self-control is significantly associated with education: the percentage of highly educated participants is equal to $33.96 \%$ among individuals with low self-control and to $52.05 \%$ for the other individuals. Also income is significantly associated with self-control, with low self-control individuals reporting lower income compared to the individuals in the other quartiles $\left(\chi^{2}(6)=20.104, p=0.003\right)$. Participants with low self-control are less likely to report always writing a shopping list (and write it in $16.98 \%$ of the cases) compared to all other individuals (who write shopping lists in $33.90 \%$ of the cases, $\chi^{2}(3)=17.416, p=0.001$ ). This relationship is interesting, as writing a shopping list can be a self-control device against excessive or unnecessary buying. Self-control is also related to having an upper limit on spending on the day of participation, with individuals with low self-control being more likely to report being budget constrained ( $12.26 \%$ of the cases) compared to other individuals $(6.16 \%$ of

\footnotetext{
${ }^{6}$ Our results do not change much if we use the total score of the BSCS. The Online Appendix reports the complete analysis based on the total score of the BSCS.
} 
the cases, $t=1.012, p=0.045)$. Individuals with low self-control report being less patient (on average 3.45 over 5 ) compared to both other individuals $\left(3.82\right.$ over $5, \chi^{2}(4)=18.243$, $p=0.001$ ), while no significant association is found when looking at the tendency toward being a maximizer $\left(\chi^{2}(8)=10.845, p=0.211\right)$.

When considering the relationship between self-control and spending behavior, we find that, overall, no significant differences exists in the total amount spent (in SEK) depending on the level of self-control (Low self-control: 414.64 SEK vs other: 463.68 SEK, $t=1.178$, $p=0.234$ ). Individuals with low self-control buy a lower number of items compared to other individuals (18.71 vs $21.98, t=1.800, p=0.073$ ). When considering the average time spent while shopping and the average time spent per item, we find that individuals with low-selfcontrol spend significantly less time compared to all other individuals (length of the shopping trip (minutes): 22.83 vs 26.53 minutes, $t=2.100, p=0.036$, but significantly higher average time per item: 2.05 vs $1.63 ; t=2.196, p=0.029)$.

So far, we have provided evidence that individuals with different levels of self-control differ in some relevant characteristics and have different shopping habits. In the next section, we will analyze the effects of using a self-scanner and how the effects interact with self-control. Moreover, we will investigate the relation between previous scanner use and self-control.

\section{Results}

We start by analyzing how using a self-scanner impacts on the total amount spent and the number of items bought (Section 4.1). Thereafter, we focus on how self-scanning affects time spent on the shopping trip (Section 4.2). At the average level, we find a small and insignificant effect of using the scanner, but we observe that effects are heterogeneous. Our results suggest that individuals with low self-control take more care and spend less money when shopping with the scanner. Hence, using a self-scanner has the potential of improving shopping for consumers with low self-control. In Section 4.3 the results suggest that consumers with low self-control are sophisticated and recognize these benefits. Subjects with low self-control are more likely to report that they used a self-scanning device prior to our study.

\subsection{Total Amount Spent, Self-Scanning and Self-Control}

In this section, we present our main result regarding the total amount spent and number of items bought on the shopping trip. Only participants who bought at least two items are considered in this and the next section. ${ }^{7}$

Result 1. Individuals with low self-control significantly reduce the total amount spent and number of items bought when using the scanner. Other individuals are not significantly

\footnotetext{
${ }^{7}$ This implies excluding four individuals from the analysis. Results are qualitatively unchanged if we include them.
} 


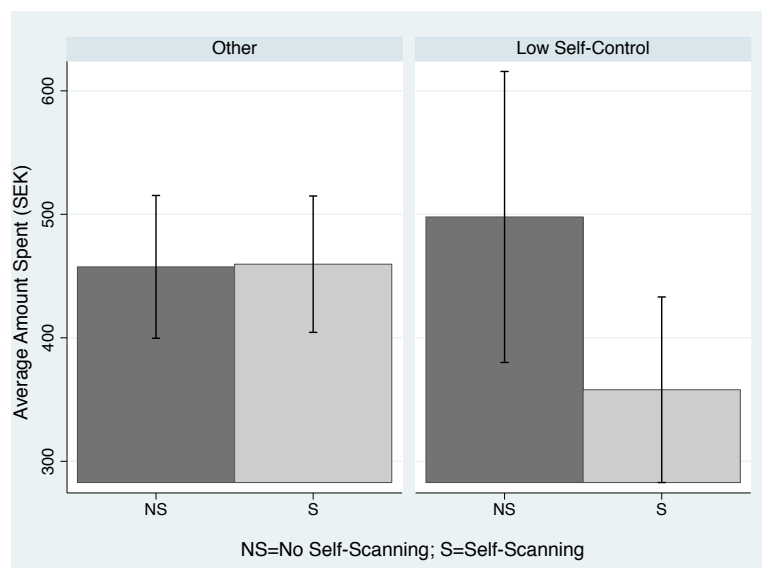

(a) Average amount spent (SEK)

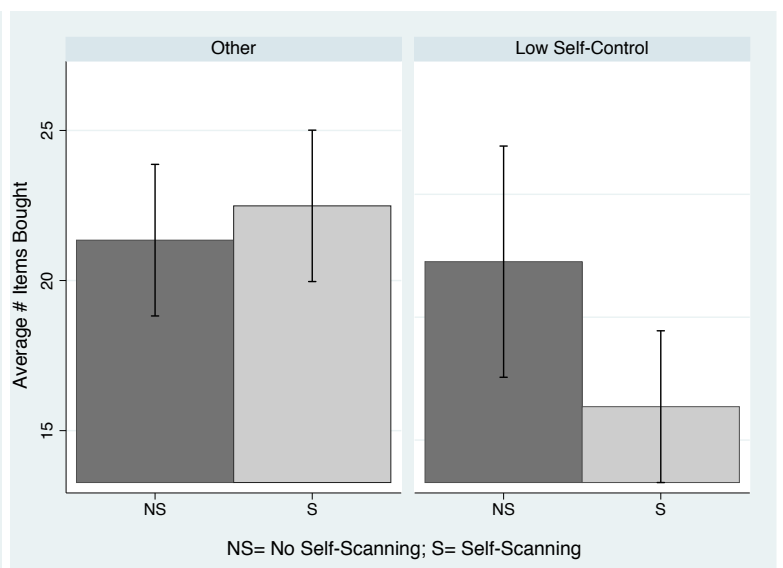

(b) Average number of items bought

Figure 1: \# of items bough, amount spent, treatment and self-control.

Note. Figures $1 a$ and $1 b$ are based on $N=394$ observations for which we have data on the BSCS and for which \# items bought> 1.

affected by using the scanner.

Result 1 is visualized in Figure 1. Panel A displays the average amount spent broken down by treatment and self-control group. The panel reveals that individuals with low self-control spend significantly less when using a self-scanner compared to when not using the scanner. The effect is sizable and amounts to a drop of around 25\%. No significant treatment effect is visible when looking at individuals in the other group with higher self-control. Similar conclusions can be drawn from Panel B, which depicts the number of items bought. Again, individuals in the low self-control group purchase significantly fewer items when using the selfscanner, while there is no treatment effect for individuals in the other group. Visual inspection is supported by a set of $t$-tests (Amount spent. Low self-control: $t=2.035, p=0.045$; Other: $t=0.118, p=0.906$. \# of items bought. Low self-control: $t=2.130, p=0.036$; Other: $t=0.610, p=0.543)$.Throughout the paper, unless noted in the text, results from the $t$-tests are unchanged if we instead use the Mann-Whitney tests. Taken together, we do not find support for a general treatment effect as stated in Hypothesis 1, but we do find a stronger effect for those with low self-control in line with Hypothesis 2.

Table 2 reports results from a set of OLS regressions investigating the relationship between the total amount spent, self-scanning and self-control. In all models, the dependent variable is represented by the total amount spent in the shopping trip and we include, as independent variables, a treatment dummy, a dummy for low self-control (which takes value 1 if the participant belongs to the low self-control group and 0 otherwise) and other observed variables such as gender, shopping alone, and dummies for each session.

In Model 1, we observe a negative but insignificant relationship between the treatment dummy and the total amount spent. Hence, overall there is no effect of using the scanner 
on total amount spent. In Model 2, we add an interaction between the treatment and the self-control dummy. Both the low self-control variable and the interaction are significant. This indicates that individuals with low self-control spend more than others when not using the scanner, but that using the scanner significantly reduces spending among the same group. Model 3 is identical to Model 2 but it does not include dummies for the length of the shopping trip. ${ }^{8}$ This reduces the size of the dummy for low self-control and it becomes insignificant, while the interaction remains negative and significant at the $10 \%$ level.

In Models 4, 5 and 6 we include a set of socio-economic control variables (e.g., age, income class, education level, occupation, etc.). We also include information about shopping habits, that is, whether the participants usually write a shopping list; has a subscription to the weekly food box program or has budget constraints for the shopping trip. Given the findings of van Ittersum et al. (2013) that the effects of providing a calculator depended on whether shoppers were budget constrained or not, we also include interactions between $i$ ) being budget constrained and treatment and $i$ ) being budget constrained and low self-control. In Models 5 and 6, additional personality traits elicited in the survey are also included: the self-reported degree of patience and attitude toward being a maximizer. We also include two dummies accounting for responding correctly to the Basic Arithmetic and the Financial Literacy questions. Model 6 is identical to Model 5; however, it does not include the dummies for the length of the shopping trip. Across Models 4 to 6 , the coefficient estimates of selfcontrol and the interaction between self-control and self-scanning are similar in magnitude and corroborate previous findings. Low self-control is associated with higher spending when not using the scanner, but scanning reduces spending in the low self-control group.

Regarding the covariates, we find that cash users spend less and the income dummies are all positive and significant. Moreover, the variable accounting for being budget constrained, is negative and significant suggesting that individuals with an upper spending limit for the shopping trip tend to spend significantly less; however, the opposite is true when they use the self-scanner, as evidenced by the positive and significant coefficient of interaction term with treatment. This result is in line with the findings in van Ittersum et al. (2013), showing that when using a self-scanner, individuals with a budget constraint are better at reaching their limits without exceeding it.

Table 3 reports results from a set of OLS regressions investigating the relationship between the number of items bought, the use of the self-scanner and low self-control. The estimated models are exactly the same as in Table 2 with the only exception being that the dependent variable is represented by the number of items bought on the shopping trip. In all models, the treatment coefficient is never significant; however, the interaction between treatment

\footnotetext{
${ }^{8}$ Given that the total amount spent also affects the length of the shopping trip, we included dummies for each of the quartiles of the distribution of the variable Length of the shopping trip. Length: Q1 includes individuals who shopped a maximum of 14 minutes; Length: Q2 includes individuals who shopped between 15 and 22 minutes; Length Q3 includes individuals who shopped between 23 and 34 minutes and Length: Q4 includes individuals who shopped more than 34 minutes.
} 
Table 2: Total amount spent (SEK) and Low Self-Control

\begin{tabular}{|c|c|c|c|c|c|c|}
\hline $\begin{array}{l}\text { Estimation Method } \\
\text { Dependent Variable }\end{array}$ & Model 1 & Model 2 & $\begin{array}{c}\text { Model } 3 \\
\text { OLS R } \\
\text { Total amoun } \\
\end{array}$ & $\begin{array}{l}\text { Model } 4 \\
\text { ression } \\
\text { spent (SEK) }\end{array}$ & Model 5 & Model 6 \\
\hline Treatment & $\begin{array}{l}-47.472 \\
(30.585)\end{array}$ & $\begin{array}{c}7.206 \\
(34.578)\end{array}$ & $\begin{array}{c}10.538 \\
(42.600)\end{array}$ & $\begin{array}{c}-3.040 \\
(34.279)\end{array}$ & $\begin{array}{c}0.358 \\
(35.346)\end{array}$ & $\begin{array}{c}2.891 \\
(44.123)\end{array}$ \\
\hline Low Self-Control & $\begin{array}{c}16.717 \\
(36.834)\end{array}$ & $\begin{array}{c}123.094^{* *} \\
(60.150)\end{array}$ & $\begin{array}{c}50.832 \\
(72.340)\end{array}$ & $\begin{array}{c}177.992^{* * *} \\
(60.996)\end{array}$ & $\begin{array}{c}188.442^{* * *} \\
(60.727)\end{array}$ & $\begin{array}{c}139.889^{* *} \\
(72.340)\end{array}$ \\
\hline $\begin{array}{l}\text { Treatment } x \\
\text { Low Self-Control }\end{array}$ & - & $\begin{array}{c}-199.024^{* * *} \\
(71.642)\end{array}$ & $\begin{array}{c}-166.164^{*} \\
(85.823)\end{array}$ & $\begin{array}{c}-205.619^{* * *} \\
(68.850)\end{array}$ & $\begin{array}{c}-209.330^{* * * *} \\
(68.673)\end{array}$ & $\begin{array}{c}-196.073^{* *} \\
(81.685)\end{array}$ \\
\hline Shopping Alone & $\begin{array}{c}38.145 \\
(34.695)\end{array}$ & $\begin{array}{c}39.798 \\
(34.119)\end{array}$ & $\begin{array}{c}-8.933 \\
(39.727)\end{array}$ & $\begin{array}{c}39.306 \\
(33.832)\end{array}$ & $\begin{array}{c}36.555 \\
(35.493)\end{array}$ & $\begin{array}{l}-22.880 \\
(42.377)\end{array}$ \\
\hline Female 1 & $\begin{array}{c}-0.191 \\
(37.140)\end{array}$ & $\begin{array}{c}4.186 \\
(36.531)\end{array}$ & $\begin{array}{c}57.119 \\
(43.987)\end{array}$ & $\begin{array}{c}20.022 \\
(35.637)\end{array}$ & $\begin{array}{c}30.864 \\
(37.528)\end{array}$ & $\begin{array}{l}91.804^{*} \\
(47.183)\end{array}$ \\
\hline Using Cash & $\begin{array}{c}-131.835^{* * *} \\
(36.722)\end{array}$ & $\begin{array}{c}-127.461^{* * *} \\
(35.782)\end{array}$ & $\begin{array}{c}-246.516^{* * *} \\
(38.725)\end{array}$ & $\begin{array}{l}-70.412^{*} \\
(36.807)\end{array}$ & $\begin{array}{c}-77.498^{* *} \\
(38.147)\end{array}$ & $\begin{array}{c}-191.093^{* * *} \\
(45.198)\end{array}$ \\
\hline Income Class: Q2 & - & - & - & $\begin{array}{c}125.211^{* * *} \\
(33.009)\end{array}$ & $\begin{array}{c}118.672^{* * *} \\
(34.436)\end{array}$ & $\begin{array}{l}77.845^{*} \\
(40.933)\end{array}$ \\
\hline Income Class: Q3 & - & - & - & $\begin{array}{c}134.963^{* * *} \\
(49.793)\end{array}$ & $\begin{array}{c}127.603^{* * *} \\
(50.701)\end{array}$ & $\begin{array}{c}100.944^{*} \\
(62.830)\end{array}$ \\
\hline Income Class: Q4 & - & - & - & $\begin{array}{c}236.777^{* * * *} \\
(51.505)\end{array}$ & $\begin{array}{c}223.109^{* * *} \\
(53.332)\end{array}$ & $\begin{array}{c}201.802^{* * *} \\
(63.178)\end{array}$ \\
\hline Budget Constrained & - & - & - & $\begin{array}{c}-218.095^{* * *} \\
(66.979)\end{array}$ & $\begin{array}{c}-218.726^{* * *} \\
(70.527)\end{array}$ & $\begin{array}{c}-168.924^{* *} \\
(78.662)\end{array}$ \\
\hline $\begin{array}{l}\text { Budget Constrainedx } \\
\text { Treatment }\end{array}$ & - & - & - & $\begin{array}{c}271.448^{* * * *} \\
(85.606)\end{array}$ & $\begin{array}{c}282.583^{* * * *} \\
(90.273)\end{array}$ & $\begin{array}{c}385.764^{* * *} \\
(116.974)\end{array}$ \\
\hline $\begin{array}{l}\text { Budget Constraine } \mathrm{x} \\
\text { Low Self-Control }\end{array}$ & - & - & - & $\begin{array}{c}-1.154 \\
(83.828)\end{array}$ & $\begin{array}{l}-14.908 \\
(89.265)\end{array}$ & $\begin{array}{c}-96.554 \\
(110.441)\end{array}$ \\
\hline Constant & $\begin{array}{c}169.456^{* * *} \\
(60.943)\end{array}$ & $\begin{array}{c}152.365^{* * *} \\
(58.492)\end{array}$ & $\begin{array}{c}412.111^{* * *} \\
(70.323)\end{array}$ & $\begin{array}{l}-39.864 \\
(86.595)\end{array}$ & $\begin{array}{l}-116.929 \\
(115.927)\end{array}$ & $\begin{array}{c}42.985 \\
(143.583)\end{array}$ \\
\hline Fixed Effects (Sessions) & Yes & Yes & Yes & Yes & Yes & Yes \\
\hline Length of the Shopping Trip & Yes & Yes & No & Yes & Yes & No \\
\hline Shopping Habits & No & No & No & Yes & Yes & Yes \\
\hline Socio-economics & No & No & No & Yes & Yes & Yes \\
\hline Personality Traits & No & No & No & No & Yes & Yes \\
\hline R-squared & 0.383 & 0.392 & 0.088 & 0.495 & 0.498 & 0.220 \\
\hline $\mathrm{F}$ & 19.647 & 18.637 & 4.493 & 12.244 & 10.303 & 3.738 \\
\hline Observations & 383 & 382 & 382 & 371 & 359 & 359 \\
\hline
\end{tabular}

Note. $^{*},{ }^{* *}$ and ${ }^{* * *}$ indicate significance level at $10 \%, 5 \%$, and $1 \%$, respectively. Robust standard errors are reported in parentheses. Only participants who bought at least 2 items are included. See Table 6 in the Online Appendix for the complete estimations. See Table 7 in the Online Appendix for estimations using the BSCS(total) rather than the dummy Low Self-Control. 
and low-self-control is always negative and significant. This suggests that individuals with low self-control significantly reduce the amount of items bought when using the self-scanner. Hence, the treatment effect for the low self-control group on the total amount spent reported in Table 2 appears to be driven by a reduction in the number of items bought. There is some indication that the number of items bought is higher for those with low self-control when not using the scanner, but the size and significance varies somewhat across models. Concerning the other covariates, the coefficient for using cash and the income dummies are all related to the number of items bought. The variable accounting for the upper limit on spending is negative and significant, while its interaction with the treatment is positive and significant.

We have also explored whether the effects of using the scanner is present across different types of products. In Table 10, 11 and 12 of the Online Appendix we report regressions using as dependent variables $i$ ) the number of items bought on discount, ii) the number of food items bought, and iii) the number of non-food items bought, respectively. For the number of items bought on discount, we do not find any significant effect related to low self-control and self-scanning. If anything, individuals who are aware of having low self-control buy less items on discount in some specifications of the model. With respect to the number of food items bought, our results are in general confirmed: individuals aware of having low self-control tend to buy more food items (at lest in some of the specifications), but when they use a self-scanner, they significantly reduce their spending on them (true for all the specifications). Finally, when considering the number of non-food items bought we do not find any significant effect related to low self-control and self-scanning. So the main effect that we observe seems to go be driven by changes in the number of food items bought.

\subsection{Time spent}

In this section, we investigate the relationship between self-control, scanner use and amount of time spent shopping. The possibility of saving time is the most common reason for using the self-scanner with $59.23 \%$ of our participants stating this motive in our survey, and this is irrespective of the level of self-control (Fisher's exact $=$ test, $p=0.180$ ). However, using a self-scanner does not necessarily reduce the time spent shopping. On the one hand, using a self-scanner does indeed save time at the end of the shopping trip, since customers do not need to stop by the cashier, where they have to stand in line, place the items bought on the payment desk and then pack them. On the other hand, when buying specific items that need to be weighted and priced by themselves (e.g., bread, fruit and vegetables), self-scanning may be slower compared to allowing the cashier do these tasks. More generally, finding each item's bar code and correctly scanning it, may require them to spend some additional time compared to those not using the self-scanner.

Since scanning was found to affect the number of items bought, we focused on the average amount of time spent per item (in minutes) and obtained dividing the total length of the 
Table 3: Number of Items Bought and Low Self-Control

\begin{tabular}{|c|c|c|c|c|c|c|}
\hline \multirow{2}{*}{$\begin{array}{l}\text { Estimation Method } \\
\text { Dependent Variable }\end{array}$} & \multicolumn{6}{|c|}{ OLS Regression } \\
\hline & \multicolumn{6}{|c|}{ Number of Items Bought $(>1)$} \\
\hline $\begin{array}{l}\text { Treatment } \\
\text { (Self-scanning) }\end{array}$ & $\begin{array}{l}-1.449 \\
(1.334)\end{array}$ & $\begin{array}{c}0.853 \\
(1.523)\end{array}$ & $\begin{array}{c}1.012 \\
(1.894)\end{array}$ & $\begin{array}{c}0.275 \\
(1.526)\end{array}$ & $\begin{array}{c}0.397 \\
(1.553)\end{array}$ & $\begin{array}{c}0.500 \\
(1.948)\end{array}$ \\
\hline Low Self-Control & $\begin{array}{l}-0.890 \\
(1.523)\end{array}$ & $\begin{array}{l}3.673 \\
(2.419)\end{array}$ & $\begin{array}{c}0.563 \\
(2.891)\end{array}$ & $\begin{array}{l}6.698^{* *} \\
(2.490)\end{array}$ & $\begin{array}{c}5.991^{* * *} \\
(2.478)\end{array}$ & $\begin{array}{l}3.905 \\
(2.974)\end{array}$ \\
\hline $\begin{array}{l}\text { Treatment } x \\
\text { Low Self-Control }\end{array}$ & - & $\begin{array}{c}-8.535^{* * *} \\
(2.933)\end{array}$ & $\begin{array}{c}-7.163^{* *} \\
(3.454)\end{array}$ & $\begin{array}{c}-9.085^{* * *} \\
(2.883)\end{array}$ & $\begin{array}{c}-9.210^{* * *} \\
(2.875)\end{array}$ & $\begin{array}{c}-8.643^{* * *} \\
(3.370)\end{array}$ \\
\hline Shopping Alone & $\begin{array}{l}0.560 \\
(1.454)\end{array}$ & $\begin{array}{c}0.622 \\
(1.421)\end{array}$ & $\begin{array}{c}-1.424 \\
(1.682)\end{array}$ & $\begin{array}{c}0.661 \\
(1.447)\end{array}$ & $\begin{array}{c}0.293 \\
(1.470)\end{array}$ & $\begin{array}{l}-2.218 \\
(1.768)\end{array}$ \\
\hline Female 1 & $\begin{array}{l}-0.341 \\
(1.655)\end{array}$ & $\begin{array}{l}-0.159 \\
(1.632)\end{array}$ & $\begin{array}{c}2.215 \\
(1.913)\end{array}$ & $\begin{array}{c}0.176 \\
(1.572)\end{array}$ & $\begin{array}{c}0.336 \\
(1.649)\end{array}$ & $\begin{array}{c}3.031 \\
(1.978)\end{array}$ \\
\hline Using Cash & $\begin{array}{c}-5.033^{* * *} \\
(1.640)\end{array}$ & $\begin{array}{c}-4.843^{* * *} \\
(1.597)\end{array}$ & $\begin{array}{c}-9.979^{* * *} \\
(1.777)\end{array}$ & $\begin{array}{l}-2.588 \\
(1.617)\end{array}$ & $\begin{array}{l}-2.786 \\
(1.703)\end{array}$ & $\begin{array}{c}-7.744^{* * *} \\
(2.087)\end{array}$ \\
\hline Income Class: Q2 & - & - & - & $\begin{array}{l}4.020^{* *} \\
(1.625)\end{array}$ & $\begin{array}{l}3.514^{* *} \\
(1.604)\end{array}$ & $\begin{array}{c}1.756 \\
(1.877)\end{array}$ \\
\hline Income Class: Q3 & - & - & - & $\begin{array}{l}5.790^{* *} \\
(2.438)\end{array}$ & $\begin{array}{l}5.376^{* *} \\
(2.496)\end{array}$ & $\begin{array}{c}4.216 \\
(2.972)\end{array}$ \\
\hline Income Class: Q4 & - & - & - & $\begin{array}{c}7.497^{* * *} \\
(2.383)\end{array}$ & $\begin{array}{c}6.763^{* * *} \\
(2.364)\end{array}$ & $\begin{array}{l}5.825^{* *} \\
(2.763)\end{array}$ \\
\hline Budget Constrained & - & - & - & $\begin{array}{c}-9.216^{* * *} \\
(2.915)\end{array}$ & $\begin{array}{c}-9.250^{* * *} \\
(2.894)\end{array}$ & $\begin{array}{c}-7.139^{* *} \\
(3.496)\end{array}$ \\
\hline $\begin{array}{l}\text { Budget Constrained } \\
\text { X Treatment }\end{array}$ & - & - & - & $\begin{array}{c}14.105^{* * *} \\
(3.852)\end{array}$ & $\begin{array}{c}14.662^{* * *} \\
(3.883)\end{array}$ & $\begin{array}{c}19.096^{* * *} \\
(5.520)\end{array}$ \\
\hline $\begin{array}{l}\text { Budget Constrained } \\
\text { X Low Self-control }\end{array}$ & - & - & - & $\begin{array}{l}-0.830 \\
(3.605)\end{array}$ & $\begin{array}{l}-1.473 \\
(3.632)\end{array}$ & $\begin{array}{l}-4.894 \\
(5.123)\end{array}$ \\
\hline Constant & $\begin{array}{c}10.406^{* * *} \\
(2.540)\end{array}$ & $\begin{array}{c}9.684^{* * *} \\
(2.422)\end{array}$ & $\begin{array}{c}20.817^{* * *} \\
(3.011)\end{array}$ & $\begin{array}{l}6.419^{*} \\
(3.558)\end{array}$ & $\begin{array}{c}4.201 \\
(5.145)\end{array}$ & $\begin{array}{l}10.773^{*} \\
(6.442)\end{array}$ \\
\hline Fixed Effects (Sessions) & Yes & Yes & Yes & Yes & Yes & Yes \\
\hline Length of the Shopping Trip & Yes & Yes & No & Yes & Yes & No \\
\hline Shopping Habits & No & No & No & Yes & Yes & Yes \\
\hline Socio-economics & No & No & No & Yes & Yes & Yes \\
\hline Personality Traits & No & No & No & No & Yes & Yes \\
\hline R-squared & 0.380 & 0.389 & 0.082 & 0.464 & 0.472 & 0.187 \\
\hline $\mathrm{F}$ & 19.872 & 18.385 & 4.061 & 11.608 & 9.554 & 3.130 \\
\hline Observations & 383 & 382 & 382 & 371 & 359 & 359 \\
\hline
\end{tabular}

Note. ${ }^{*},{ }^{* *}$ and ${ }^{* * *}$ indicate significance level at $10 \%, 5 \%$, and $1 \%$, respectively. Robust standard errors are reported in parenthesis. Only participants who buy at least 2 items are included. See Table 8 in the Online Appendix for the complete estimations. See Table 9 in the Online Appendix for estimations using the BSCS(total) rather than the dummy Low Self-Control. 
shopping trip (in minutes) by the number of items bought. The Online Appendix contains a detailed analysis of the average length of the shopping trip, depending on using the selfscanner or not.

We start by summarizing our findings in the following result.

Result 2. When considering the average time spent per item bought, participants with low self-control using a self-scanner are significantly slower than both i) other low self-control individuals not using the self-scanner and ii) other individuals, irrespectively of using the selfscanner or not. When self-scanner is not used, differences in the average amount of time spent per item bought depending on self-control are not significant.

Figure 2 displays the average amount of time spent per item bought depending on treatment and self-control. It is evident from the figure that low self-control individuals using the scanner take more time than the other individuals. We find that individuals with low self-control significantly increase the average time spent per item bought when using the scanner compared to when not using it $(t=1.780, p=0.075$; Mann-Whitney test: $z=3.035$, $p=0.002$ ). Similarly, we observe that the low self-control individuals with scanners take more time than the other (no low self-control) individuals using the self-scanner (t-test: $t=2.040$, $p=0.043)$ or not using the self-scanner (t-test: $t=2.010, p=0.046)$.

When merging the two self-control groups, we observe no average treatment effect (t-test, $t=1.158, p=0.248)$ and similarly we observe no differences when comparing individuals depending on low self-control (t-test, $t=1.250, p=0.261$ ). The results again suggest that using a self-scanner has a different effect, depending on the individuals' level of self-control. If the effectiveness of the self-scanner as a self-control device is generated by costs and the total amount spent becomes more salient, individuals with low self-control may spend more time deciding whether to buy a certain item when using a self-scanner.

Table 4 reports results from a set of OLS regressions that further investigates the relationship between the average time spent per item bought and low self-control. In all models, the dependent variable is the average time used per item bought (in minutes) in the shopping trip and it is obtained by dividing the length of the shopping trip by the number of items bought. The set of independent variables are similar to those in Tables 2 and 3 .

In all models, the treatment dummy is not significant, while the dummy Low Self-control is negative and significant in Models 3 and 4, suggesting that individuals with low self-control are significantly faster when shopping compared to individuals with no low self-control. At the same time, the interaction between the treatment and the low self-control dummy is positive and significant in all models, highlighting the effect of using a self-scanner for individuals with low self-control. Taken together, these results indicate that individuals exhibiting low self-control react quite differently to the use of self-scanner compared to others, devoting significantly more time per item when using the self-scanner. One interpretation of this 
Table 4: Average time used for item bought

\begin{tabular}{|c|c|c|c|c|}
\hline $\begin{array}{l}\text { Estimation Method } \\
\text { Dependent Variable }\end{array}$ & \multicolumn{4}{|c|}{$\begin{array}{c}\text { OLS Regression } \\
\text { Average time used per item (minutes) }\end{array}$} \\
\hline $\begin{array}{l}\text { Treatment } \\
\text { (Self-scanning) }\end{array}$ & $\begin{array}{c}0.173 \\
(0.140)\end{array}$ & $\begin{array}{l}-0.006 \\
(0.142)\end{array}$ & $\begin{array}{c}0.089 \\
(0.114)\end{array}$ & $\begin{array}{c}0.089 \\
(0.118)\end{array}$ \\
\hline Low Self-Control & $\begin{array}{c}0.126 \\
(0.176)\end{array}$ & $\begin{array}{l}-0.227 \\
(0.228)\end{array}$ & $\begin{array}{c}-0.399^{* *} \\
(0.170)\end{array}$ & $\begin{array}{c}-0.381^{* *} \\
(0.173)\end{array}$ \\
\hline $\begin{array}{l}\text { Treatment } \mathrm{x} \\
\text { Low Self-Control }\end{array}$ & - & $\begin{array}{l}0.661^{*} \\
(0.382)\end{array}$ & $\begin{array}{c}0.706^{* *} \\
(0.306)\end{array}$ & $\begin{array}{c}0.700^{* *} \\
(0.312)\end{array}$ \\
\hline Shopping Alone & $\begin{array}{l}0.245^{*} \\
(0.137)\end{array}$ & $\begin{array}{l}0.234^{*} \\
(0.136)\end{array}$ & $\begin{array}{c}0.179 \\
(0.129)\end{array}$ & $\begin{array}{c}0.171 \\
(0.148)\end{array}$ \\
\hline Female 1 & $\begin{array}{c}0.034 \\
(0.164)\end{array}$ & $\begin{array}{c}0.015 \\
(0.168)\end{array}$ & $\begin{array}{c}0.037 \\
(0.129)\end{array}$ & $\begin{array}{c}0.046 \\
(0.148)\end{array}$ \\
\hline Using Cash & $\begin{array}{c}0.658^{* *} \\
(0.277)\end{array}$ & $\begin{array}{c}0.647^{* *} \\
(0.273)\end{array}$ & $\begin{array}{c}0.266 \\
(0.171)\end{array}$ & $\begin{array}{c}0.235 \\
(0.179)\end{array}$ \\
\hline Income Class: Q2 & - & - & $\begin{array}{l}-0.198 \\
(0.168)\end{array}$ & $\begin{array}{l}-0.187 \\
(0.176)\end{array}$ \\
\hline Income Class: Q3 & - & - & $\begin{array}{c}-0.351^{*} \\
(0.212)\end{array}$ & $\begin{array}{c}-0.358^{*} \\
(0.215)\end{array}$ \\
\hline Income Class: Q4 & - & - & $\begin{array}{c}-0.447^{* *} \\
(0.189)\end{array}$ & $\begin{array}{c}-0.435^{* *} \\
(0.193)\end{array}$ \\
\hline Budget Constrained & - & - & $\begin{array}{c}1.812^{* * *} \\
(0.625)\end{array}$ & $\begin{array}{c}1.845^{* * *} \\
(0.611)\end{array}$ \\
\hline $\begin{array}{l}\text { Budget Constrained } \mathrm{x} \\
\text { Treatment }\end{array}$ & - & - & $\begin{array}{c}-2.222^{* * *} \\
(0.605)\end{array}$ & $\begin{array}{c}-2.218^{* * *} \\
(0.585)\end{array}$ \\
\hline $\begin{array}{l}\text { Budget Constrained x } \\
\text { Low Self-Control }\end{array}$ & - & - & $\begin{array}{l}-0.358 \\
(0.680)\end{array}$ & $\begin{array}{l}-0.345 \\
(0.663)\end{array}$ \\
\hline Constant & $\begin{array}{c}0.960^{* * *} \\
(0.215)\end{array}$ & $\begin{array}{c}1.025^{* * *} \\
(0.213)\end{array}$ & $\begin{array}{c}1.164^{* * *} \\
(0.383)\end{array}$ & $\begin{array}{l}1.085^{*} \\
(0.522)\end{array}$ \\
\hline Fixed Effects (Sessions) & Yes & Yes & Yes & Yes \\
\hline Socio-Economics & No & No & Yes & Yes \\
\hline Other Shopping Habits & No & No & Yes & Yes \\
\hline Personality Traits & No & No & No & Yes \\
\hline R-squared & 0.079 & 0.089 & 0.227 & 0.234 \\
\hline $\mathrm{F}$ & 1.972 & 1.931 & 3.122 & 2.653 \\
\hline Observations & 377 & 376 & 365 & 354 \\
\hline
\end{tabular}

Note. ${ }^{*},{ }^{* *}$ and ${ }^{* * *}$ indicate significance level at $10 \%, 5 \%$, and $1 \%$, respectively. Robust standard errors are reported in parentheses. Only participants who bought at least 2 items are included. See Table 13 in the Online Appendix for the complete estimations. See Table 14 in the Online Appendix for estimations using the BSCS (total) rather than the dummy Low Self-Control. 


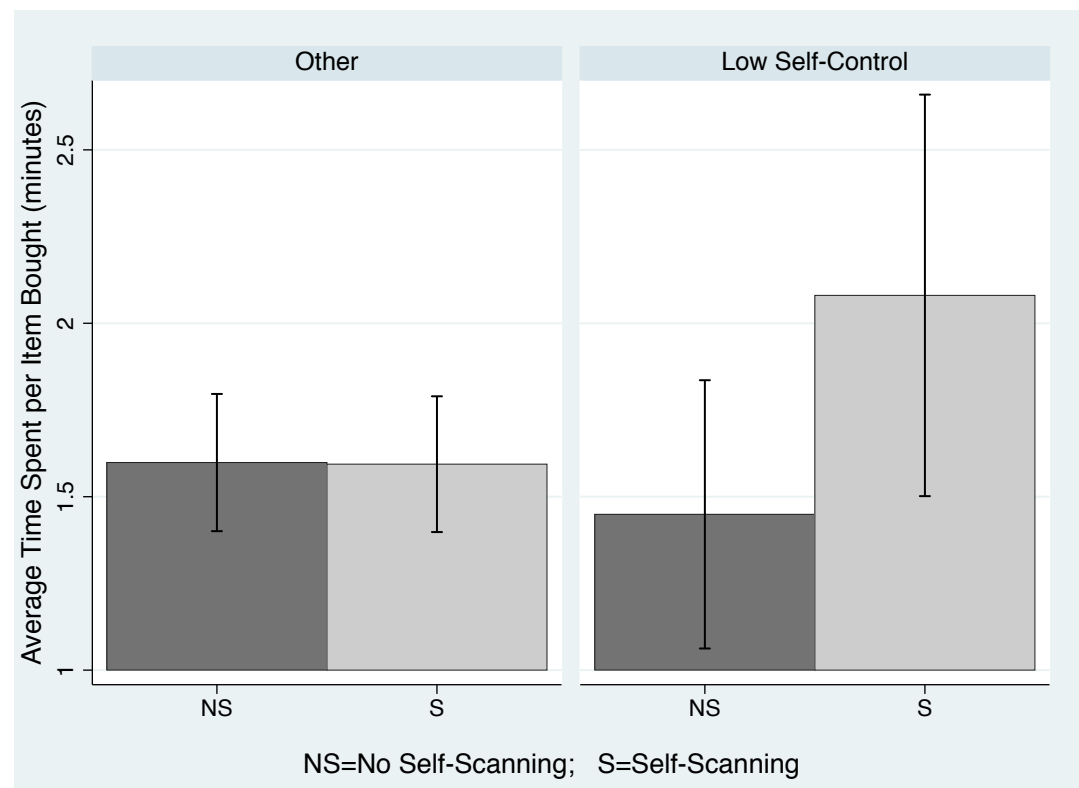

Figure 2: Average time spent per item bought depending on treatment and self-control. Note. Results are based on $N=385$ observations for which we have data on the BSCS and for which \# items bought $>1$.

finding is that in absence of the self-scanner, low self-control shoppers are more prone to impulsive buying, which implies thoughtlessly adding items to the shopping cart, which may be quicker than making more deliberate purchases.

Regarding the covariates, in Models 1 and 2, we also find that shopping alone and using cash significantly increase the average time spent per item. However, these variables are related to other background variables and the coefficient becomes insignificant in Models 3 and 4, when we include other control variables. For Models 3 and 4, we find that being in the upper income quartiles has a negative and significant effect on the average amount of time spent. One explanation could be that individuals with higher incomes must spend less time in considering the prices of the items they are buying, so they move faster. As an alternative, one may think that time for them has a higher opportunity cost, so they are - on averagewilling to devote less time to shopping. In both Models 3 and 4, reporting having an upper limit on spending on the shopping trip has a positive and significant effect on the dependent variable, suggesting that individuals having budget constraints may spend some time making considerate choices or calculating how far they are from their limits. The interaction between reporting an upper limit on spending and the treatment has a negative and significant effect, suggesting that a self-scanner is helpful in allowing shoppers to monitor the total amount spent and save time. These results are in line with the finding in van Ittersum et al. (2013). Correctly answering the question about basic arithmetic is significantly related to time use, whereas the effects of other variables such as age, number of children in the household, writing shopping lists, employment and education are not statistically significant. 


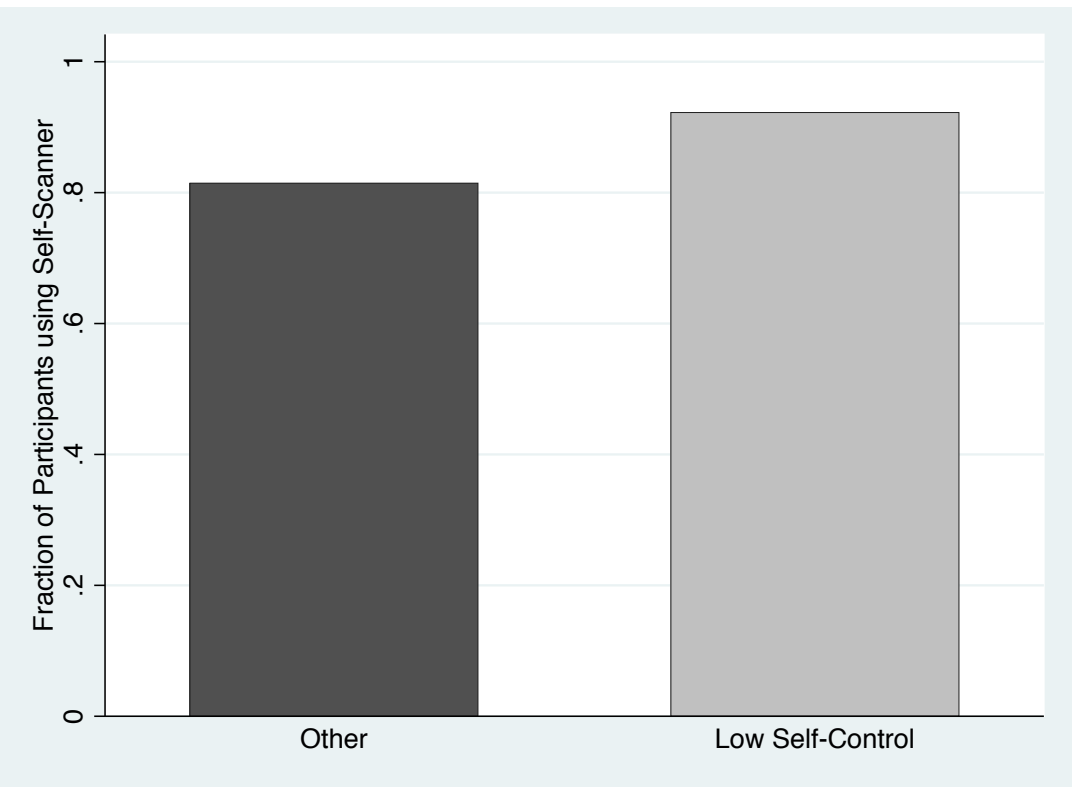

Figure 3: Fraction of participants using self-scanner and self-control level

Taken together, we do not find support for Hypothesis 3, since using a self-scanner does not seem to affect the length of the shopping trip overall; however, we do find that individuals with low self-control become slower when using a self-scanner, in line with Hypothesis 4.

\subsection{The use of self-scanner and the level of self-control}

The results in the previous sections reveal that self-scanning can be a powerful device for making more considerate shopping decisions and keeping spending under control, for individuals with low self-control. If individuals with low self-control are aware of their self-control problems and the potential support offered by the self-scanner, they may be more likely to use the device than other individuals. In this section, we find that this is indeed the case.

Result 3. Individuals with low self-control are more likely to have used the self-scanner prior to our study.

Support for Result 3 is displayed in Figure 3, which illustrates the fraction of participants who report having used a self-scanner prior to our study. It can be noted that this fraction is higher for individuals having low self-control, suggesting that individuals who report having low self-control are more likely to use self-scanner in our sample, $\left(\chi^{2}(1)=7.438, p=0.006\right)$.

To get a more complete picture of why individuals use the self-scanner, we estimated a series of Probit regressions of the propensity to report being a self-scanner user or not. The complete estimations are reported in Table 4 in the Online Appendix. Here, we summarize our main findings: in all models, the low self-control dummy is positively and significantly associated with being a self-scanner user, with the individuals exhibiting low self-control being 
about $16 \%$ more likely to report being a self-scanner user compared to individuals who do not exhibit low self-control. These results suggest that self-scanning may be also used as a self-control device by individuals reporting to have low self-control.

\section{Conclusion}

Our study provides strong evidence for self-control being an important determinant of shopping behavior. We also show that the impact of feedback technology on shopping behavior can be heterogenous and depend on personal traits. Specifically, we analyze how using a self-scanner impacts on shopping behavior. At the average level, we find no effect of using the scanner in contrast to van Ittersum et al. (2013), indicating that retailers do not need not to be overly worried of potential negative effects on sales. However, we do observe that the effects of scanner use are heterogeneous and related to self-control. Subjects with low self-control buy fewer items and spend less money when using the self-scanner. Moreover, individuals with low self-control spend more time shopping when using the scanner. Taken together, these results suggest that individuals with low self-control take more care and spend less money when shopping with the scanner. Hence, using a self-scanner has the potential of improving shopping for consumers with low self-control. Relating self-control with selfreported scanner use, we find evidence that consumers with low self-control are sophisticated and recognize these benefits. Subjects with low self-control report that they are more likely to have previously used mobile self-scanning.

Self-scanners are often marketed as a way for customers to save time. Even though we do not find support for this, it is still possible that the consumer experience is enhanced due to more productive time usages. More time is spent in the store, rather than in the queue, enabling more thoughtful shopping decisions. The consumer experience is also likely to be augmented by the fact that keeping track of shopping expenditures generates stress (cf. Van Ittersum et al. (2010)) and the scanner makes this activity less cognitive demanding. Mobile self-scanners offers several other potential benefits not addressed in this study such as target advertisement and day and time specific information about promotions etc.

The underlying mechanism behind the effect of scanner use on self-control remains an interesting avenue for future research. One potential mechanism is that subjects have limited attention and the displayed prices places extra focus on the costs involved. Thunström \& Ritten (2017) report that spendthrifty shoppers pay less attention to prices. Their measure of spendthriftiness is highly correlated with the self-control measure we employ, which suggests that low self-control subjects may be particularly responsive to feedback information on prices and the total amount spent. Moreover, it could be that such focus on costs interrupts the flow of shopping, mitigating the shopping momentum effect (Dhar et al. 2007). An alternative but related mechanism is that shoppers have multiple goals such as keeping costs low, buying 
quality products and planning for the long term (cf. Fishbach \& Dhar (2005)). The price feedback may then lead to a focus on cost aspects at the expense of other goals. Understanding the dynamic effects of real-time feedback is also a path for future studies. Low-self control shoppers may compensate the reduction in spendings with more frequent shopping trips.

\section{References}

Achtziger, A., Hubert, M., Kenning, P., Raab, G. \& Reisch, L. (2015), 'Debt out of control: The links between self-control, compulsive buying, and real debts', Journal of Economic Psychology 49, 141-149.

Baumeister, R. F. (2002), 'Yielding to temptation: Self-control failure, impulsive purchasing, and consumer behavior', Journal of Consumer Research 28(4), 670-676.

Baumeister, R. F., Sparks, E. A., Stillman, T. F. \& Vohs, K. D. (2008), 'Free will in consumer behavior: Self-control, ego depletion, and choice', Journal of Consumer Psychology 18(1), 4-13.

Calzolari, G. \& Nardotto, M. (2016), 'Effective Reminders', Management Science . forthcoming.

Chetty, R., Looney, A. \& Kroft, K. (2009), 'Salience and taxation: Theory and evidence', American Economic Review 99(4), 1145-1177.

Clerides, S. \& Courty, P. (2017), 'Sales, quantity surcharge, and consumer inattention', The Review of Economics and Statistics 99(2), 357-370.

Dhar, R., Huber, J. \& Khan, U. (2007), 'The Shopping Momentum Effect', Journal of Marketing Research 44(3), 370-378.

Dickson, P. R. \& Sawyer, A. G. (1990), 'The Price Knowledge and Search of Supermarket Shoppers', Journal of Marketing 54(3), 42-53.

Fishbach, A. \& Dhar, R. (2005), 'Goals as excuses or guides: The liberating effect of perceived goal progress on choice', Journal of Consumer Research 32(3), 370-377.

Gneezy, A. (2017), 'Field Experimentation In Marketing Research', Journal of Marketing Research 54(1), 140-143.

Inman, J. J., Ferraro, R. \& Winer, R. S. (2004), 'Where the Rubber Meets the Road: A Model of In-Store Consumer Decision-Making', mimeo .

Karlan, D., McConnell, M., Mullainathan, S. \& Zinman, J. (2016), 'Getting To the Top of Mind: How Reminders Increase Saving', Management Science 62(12), 3393-3411. 
Lusardi, A. \& Mitchell, O. S. (2008), 'Planning and Financial Literacy: How Do Women Fare?', American Economic Review: Papers $\&$ Proceedings 98(2), 413-417.

Meier, S. \& Sprenger, C. (2010), 'Present-biased preferences and credit card borrowing', American Economic Journal: Applied Economics 2(1), 193-210.

Milkman, K. L., Beshears, J., Choi, J. J., Laibson, D. \& Madrian, B. C. (2011), 'Using implementation intentions prompts to enhance influenza vaccination rates.', Proceedings of the National Academy of Sciences of the United States of America 108(26), 10415-20.

O'Donoghue, T. \& Rabin, M. (1999), 'Doing it now or later', American Economic Review pp. 103-124.

Schwartz, B., Ward, A., Monterosso, J., Lyubomirsky, S., White, K. \& Lehman, D. R. (2002), 'Maximizing versus satisficing: happiness is a matter of choice.', Journal of personality and social psychology 83(5), 1178-1197.

Stango, V. \& Zinman, J. (2014), 'Limited and varying consumer attention: Evidence from shocks to the salience of bank overdraft fees', Review of Financial Studies 27(4), 990-1030.

Tangney, J. P., Baumeister, R. F. \& Boone, A. L. (2004), 'High self-control predicts good adjustment, less pathology, better grades, and interpersonal success.', Journal of personality 72(2), 271-324.

Thunström, L. \& Ritten, C. J. (2017), 'Endogenous attention to costs', mimeo .

Van Ittersum, K., Pennings, J. M. E., Wansink, B., Blount, J., Maximenko, A., Monke, K., Pennings, V., Reeves, A., Scherer, S., Van Ittersum, M., Wansink, J. \& Williams, H. (2010), 'Trying Harder and Doing Worse: How Grocery Shoppers Track In-Store Spending', Journal of Marketing 74(March), 90-104.

van Ittersum, K., Wansink, B., Pennings, J. M. E. \& Sheehan, D. (2013), 'Smart shopping carts: How real-time feedback influences spending', Journal of Marketing 77(6), 21-36.

Wincor-Nixdorf (2015), 'Mobile self-scanning', http://www.wincor-nixdorf . com/internet/cae/servlet/contentblob/1310968/publicationFile/87054/ MobileSelfScanning-Broschuere.pdf [Accessed: 2017-03-22]. 


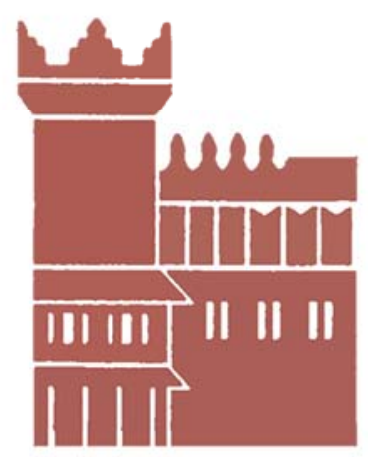

Alma Mater Studiorum - Università di Bologna DEPARTMENT OF ECONOMICS

Strada Maggiore 45

40125 Bologna - Italy

Tel. +39051 2092604

Fax +390512092664

http://www.dse.unibo.it 